\title{
Arrest in ciliated cell expansion on the bronchial lining of adult rats caused by chronic exposure to industrial noise
}

\author{
Maria João R. Oliveira ${ }^{\mathrm{a}, *}$, António S. Pereira ${ }^{\mathrm{a}}$, Paula G. Ferreira ${ }^{\mathrm{a}}$, Laura Guimarães ${ }^{\mathrm{b}}$, \\ Diamantino Freitas $^{\mathrm{c}}$, António P.O. Carvalho ${ }^{\mathrm{c}}$, Nuno R. Grande ${ }^{\mathrm{a}}$, Artur P. Águas ${ }^{\mathrm{a}}$ \\ ${ }^{a}$ Department of Anatomy, ICBAS, Abel Salazar Institute for Biomedical Sciences, UMIB, University of Porto, Largo Prof. Abel Salazar, 2, \\ 4099-033 Porto, Portugal \\ ${ }^{\mathrm{b}}$ Department of Population Studies, ICBAS, Abel Salazar Institute for Biomedical Sciences, University of Porto, 4099-033 Porto, Portugal \\ ${ }^{\mathrm{c}}$ Engineering Faculty, Polo da Asprela, University of Porto, 4200-465 Porto, Portugal
}

Received 13 December 2003; received in revised form 28 May 2004; accepted 10 June 2004

Available online 20 July 2004

\begin{abstract}
Workers chronically exposed to high-intensity/low-frequency noise at textile plants show increased frequency of respiratory infections. This phenomenon prompted the herein investigation on the cytology of the bronchial epithelium of Wistar rats submitted to textile noise. Workplace noise from a cotton-mill room of a textile factory was recorded and reproduced in a sound-insulated animal room. The Wistar rats were submitted to a weekly schedule of noise treatment that was similar to that of the textile workers ( $8 \mathrm{~h}$ /day, 5 days/week). Scanning electron microscopy (SEM) was used to compare the fine morphology of the inner surface of the bronchi in noise-exposed and control rats. SEM quantitative cytology revealed that exposure to noise for 5-7 months caused inhibition in the natural expansion of the area occupied by ciliated cells on the bronchial epithelium as adult rats grow older. This difference between noise-exposed and age-matched control rats was statistically significant $(P<0.05)$ and documents that the cytology of the rat bronchial epithelium is mildly altered by noise exposure. The decrease in the area of bronchial cilia may impair the mucociliar clearance of the respiratory airways and, thus, increase vulnerability to respiratory infection.
\end{abstract}

(C) 2004 Elsevier Inc. All rights reserved.

Keywords: Scanning electron microscopy; Morphometry; Noise; Vibration; Membrane

\section{Introduction}

Recent decades have revealed mounting evidence that chronic exposure to excessive noise may cause systemic disorders, in addition to the well-established damage to hearing (Parvizpoor, 1976; Knipschild, 1977, 1978; Knipschild et al., 1981; Melamed and Bruhis, 1996; Nicholas et al., 1998). Noise-related disorders have been identified in exposed workers and have led to the concept of vibroacoustic disease (VAD) (Castelo Branco, 1999; Castelo Branco and Rodriguez, 1999; Alves Pereira, 1999). Investigation of VAD prevalence is of particular importance in workers of industries where

\footnotetext{
${ }^{*}$ Corresponding author. Fax: + 351-2-2062232.

E-mail address: mjolivei@icbas.up.pt (M.J.R. Oliveira).
}

noise prevails (e.g., airplane and textile plants). Taking into account that textile workers show increased frequency of respiratory infections (Fishwick et al., 1996; Cloutier and Guernsey, 1998; Simpson et al., 1998; Raza et al., 1999), this investigation aimed at finding out whether the bronchial epithelium undergoes any cytological change in animals chronically exposed to cottonmill-room noise. Scanning electron microscopy (SEM) was used to perform quantitative cytology of the bronchial epithelium of noise-exposed and control rats.

The herein data document that exposure of Wistar rats to cotton-mill-room noise inhibits the physiological enhancement in the ciliated area of the bronchi that is normally observed as young rats grow older. This significant difference in the area occupied by bronchial ciliated cells suggests that chronic exposure to textile 
noise may moderately decrease the functional ability of the mucociliary apparatus of the respiratory tract.

\section{Materials and methods}

\subsection{Animals and experimental groups}

Forty adult male Wistar rats were kept in our animal house until they were 8 weeks old. The rats had been purchased from a Spanish breeder (Charles River Laboratories España, S.A., Spain). All animals had unrestricted access to food (commercial chow) and water. Standard house conditions were used and they involved keeping two rats in a plastic cage $(42 \times 27 \times$ $16 \mathrm{~cm}$ ) with a steel lid. Half of the rats were exposed to noise, and half of them were used as age-matched controls.

Rats exposed to noise were submitted to different periods of noise exposure, ranging from 1 to 7 months, according to an occupationally simulated time schedule ( $8 \mathrm{~h} /$ day; 5 days/week with weekends in silence). The 20 rats were divided into four groups and sacrificed after 1 , 3 , 5, and 7 months of noise exposure. They were, therefore, 3, 5, 7, and 9 months old when they were sacrificed. The remaining $20 \mathrm{Wistar}$ rats were used as age-matched controls (no noise exposure) and thus sacrificed when they were 3, 5, 7, and 9 months old.

\subsection{Scanning electron microscopy}

The rats were sacrificed by a lethal intravenous injection of sodium-pentobarbital $(40 \mathrm{mg} / \mathrm{kg})$ and the left lungs excised and processed for SEM. The samples were fixed in toto in a solution of $3 \%$ glutaraldehyde in $0.1 \mathrm{M}$ phosphate buffer, $\mathrm{pH} 7.2$, washed in several changes of $5 \%$ sucrose in $0.1 \mathrm{M}$ phosphate buffer, $\mathrm{pH}$ 7.2, dehydrated, critical-point-dried, and coated with gold (Zagalo et al., 2001; Oliveira et al., 2002). Observations of the samples by SEM (JEOL JSM$6301 \mathrm{~F}$, Japan) were performed at an accelerating voltage of $10 \mathrm{kV}$.

\subsection{Quantification of the relative area occupied by different cell types}

Random SEM micrographs of the samples were obtained at a magnification of $\times 1000$. Ten micrographs were made of each sample; a total area of $0.11 \mathrm{~mm}^{2}$ of the bronchial epithelium was used for quantitative analysis of each sample. The relative areas of the bronchial surface that were coated by ciliated cells, secretory cells, brush cells, or other unidentifiable cells were determined with the help of a transparent grid of 20 points, spaced $4 \mathrm{~cm}$ from each other, that was superimposed on the printed micrographs (Oliveira et al., 2002). The numerical values of the relative areas of the bronchial epithelium covered by the different cell types were calculated using the following formula: total points of ciliated or other cell types/total points of the grid inside the micrograph. The data are presented as the average proportion of area.

\subsection{Statistical analysis}

All values are reported as mean \pm SE. A strong correlation between the relative areas occupied by ciliated and those by secretory cells was documented by computing the partial correlation coefficient, after controlling for exposure to noise and duration of the exposure $(r=-0.9774, \quad P<0.001)$. Therefore, only differences among the experimental groups with regard to the relative area occupied by ciliated cells were analyzed. The proportions of area occupied by ciliated cells in controls and in animals submitted to several durations of noise exposure were compared by using least-squares analyses of variance. Arcsine transformation of the data (angle $=\arcsin \sqrt{\text { proportion }}$ ) was used because of nonnormality. Statistical significance was accepted for $P<0.05$. Statistical procedures were carried out on LSMLMW (Harvey, 1990).

\subsection{Noise exposure}

The environmental noise of a cotton-mill room from a large textile factory of northern Portugal was used as the paradigm of the occupational noise to which textile workers are submitted.

The noise present in this cotton-mill room was recorded and reproduced. An electroacoustic setup was adopted; it employed a PC-based system, with a DT2823 data acquisition card and a SB Live 5.1 card, one B\&K 4165 microphone with preamplifier, one twochannel power amplifier, and 16 monitor-type and 1 subwoofer loudspeakers in biamplification. The software was designed using the LabVIEW system. Sound signal processing was done offline, applying LabVIEW and Matlab systems. This apparatus was capable of recording and reproducing the specified noise sounds while monitoring the saturation level in the amplitude dynamic range. A $99.7 \%$ dynamic range was preserved for all signals. Signal acquisition and processing methodologies were designed to carefully measure and preserve the sound characteristics. Total signal duration was $1 \mathrm{~h}$. Frequency and amplitude characterization of signals was done for all samples. Reproduction of sounds at the original levels of approximately $92 \mathrm{~dB}$ (with spectrum very near the original one) was achieved by equalization and distribution of sound output in the room. The spectrum of frequencies and intensities of the noise used in this study is documented in Fig. 1. 


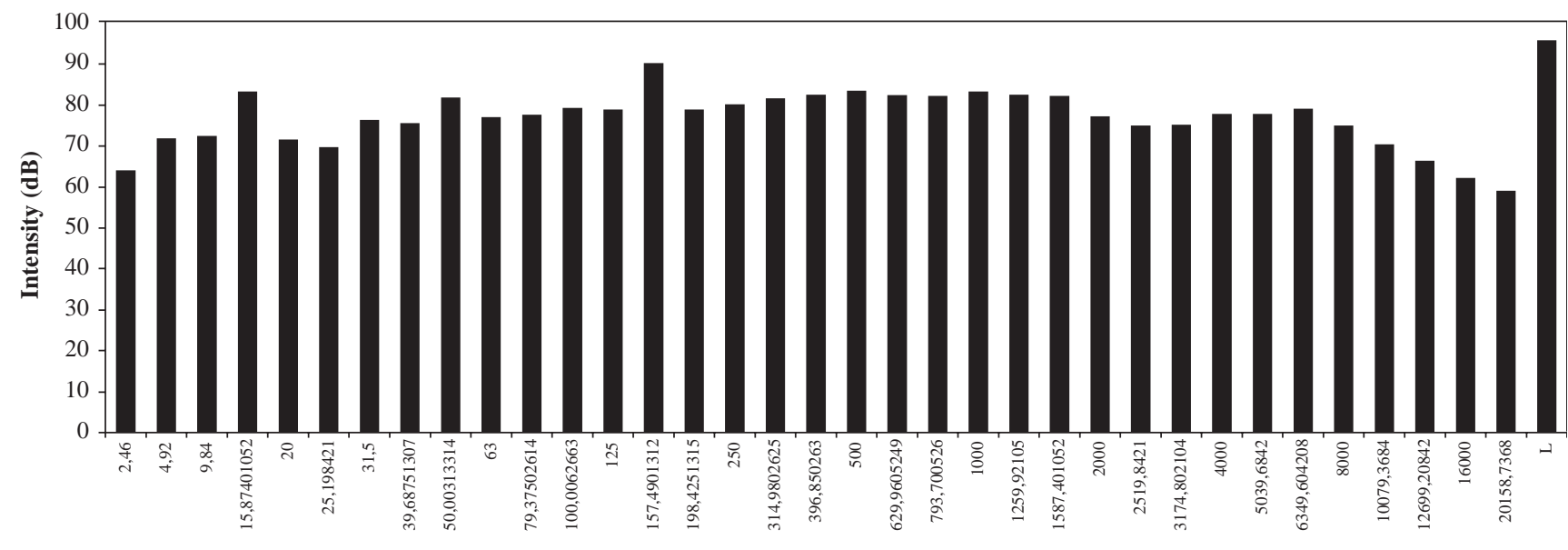

Frequency $(\mathrm{Hz})$

Fig. 1. Spectrum of frequencies and intensities of the textile-type noise that was recorded in a cotton-mill room and reproduced in the animal house room where the Wistar rats were kept and exposed to noise.

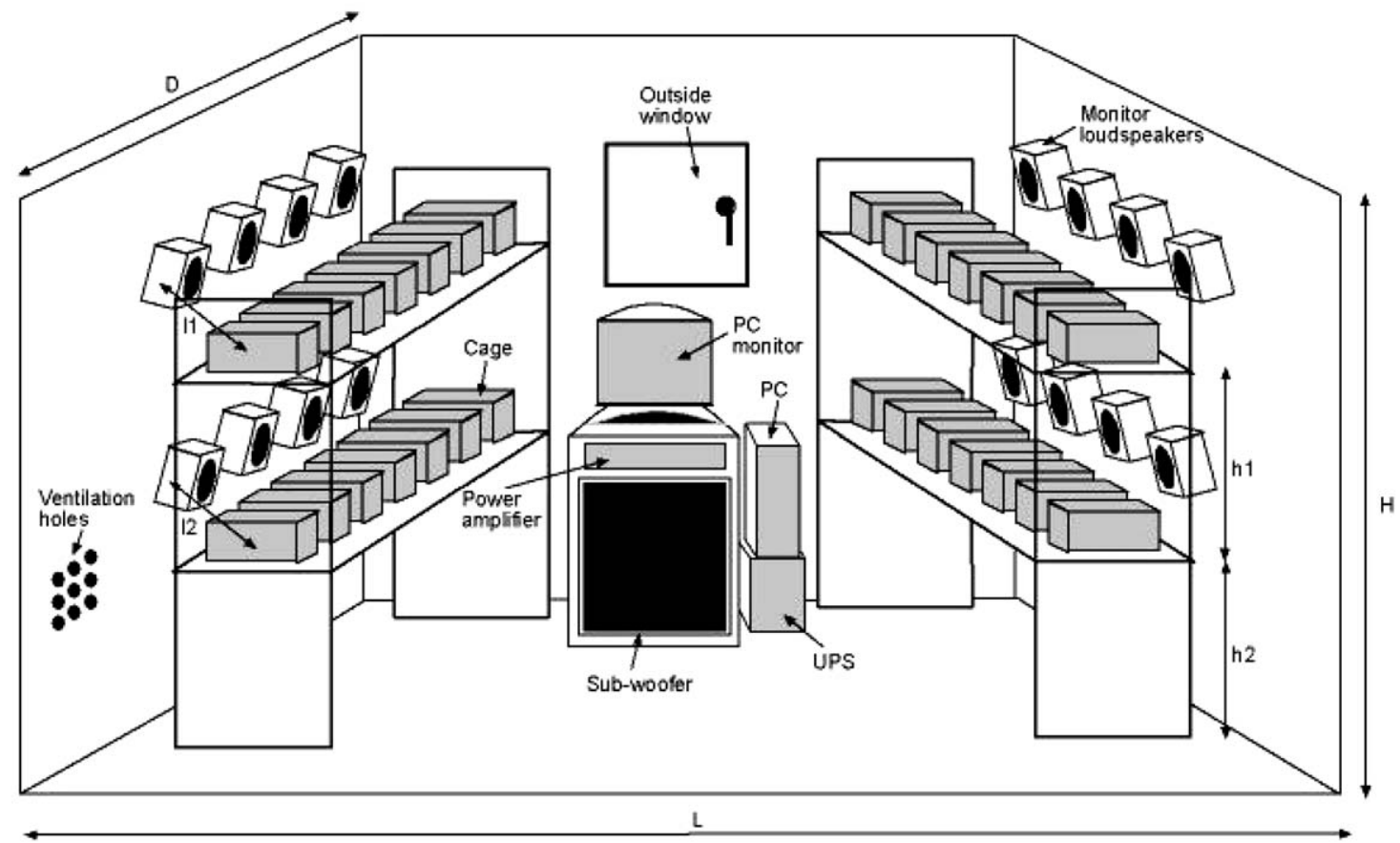

Fig. 2. Spatial organization of the animal room where Wistar rats were exposed to textile-type noise. The dimensions of the room were the following: L, $3.02 \mathrm{~m}$; D, $3.08 \mathrm{~m}$; H, $2.90 \mathrm{~m}$.

The recorded noise was then reproduced in a soundinsulated animal room, where the rats were to be exposed to it. The sound characterization and room equalization were done by means of a 35 -filter bank composed of 3 low-frequency 1-octave bandpass filters and 32 1/3-octave bandpass filters for the upper bands. All filters had $50 \mathrm{~dB}$ selectivity. The average sound pressure level in the room and the dispersion of values among cages was carefully controlled. The final sound pressure values that were obtained, measured with a quality calibrated soundmeter, were within a $3-\mathrm{dB}$ tolerance relative to the original values, and the dispersion of values among cages was also inside a tolerance of $3 \mathrm{~dB}$ relative to the referenced average. The detailed spatial organization of the room where the rats were exposed to noise is illustrated in Fig. 2.

\section{Results}

SEM was used here to define the detailed structure of the luminal surface of bronchi of Wistar rats submitted 
to industrial noise. To quantitatively compare samples from noise-exposed and age-matched control animals, SEM micrographs were randomly taken of the bronchial lining in both groups of rats. Based on these micrographs, the relative areas occupied by the several cell types that make up the luminal surface of the bronchi were determined. SEM observations confirmed that the ciliated cell was the predominant cell type on the bronchial epithelium of the rat. They occupied around $75 \%$ of the epithelial surface of the bronchi (Figs. 3 and 4).

In control rats, an increase with age (from 3 to 9 months) was found with regard to the area occupied by ciliated cells on the bronchial lining. In fact, 7- and 9month-old animals had larger proportions of the bronchial surface covered by ciliated cells than that observed in younger control rats (3- and 5-month-old animals). Chronic exposure of rats to textile-mill noise

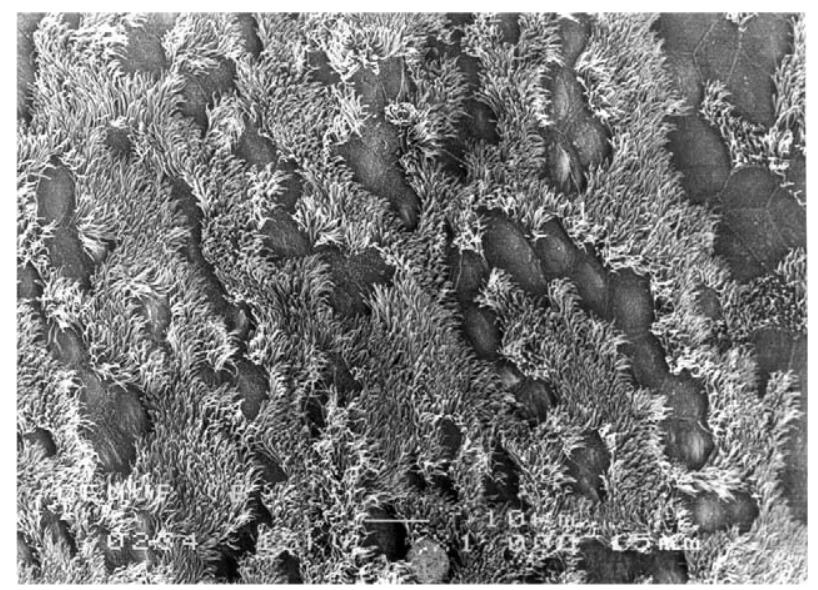

Fig. 3. SEM micrograph of the bronchial surface of Wistar rat showing a high density of ciliated cells in a control animal $(\times 1000)$.

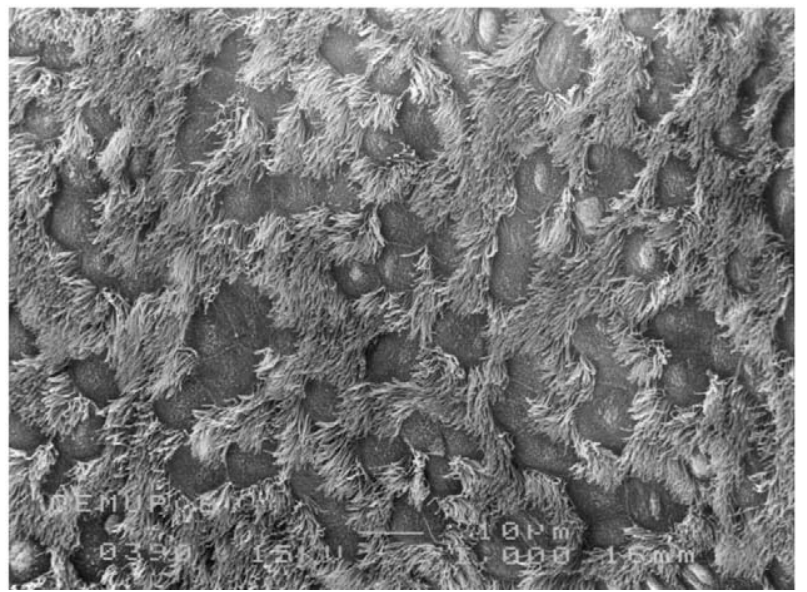

Fig. 4. SEM micrograph of the bronchial surface of Wistar rat showing a high density of ciliated cells in a noise-exposed animal $(\times 1000)$.

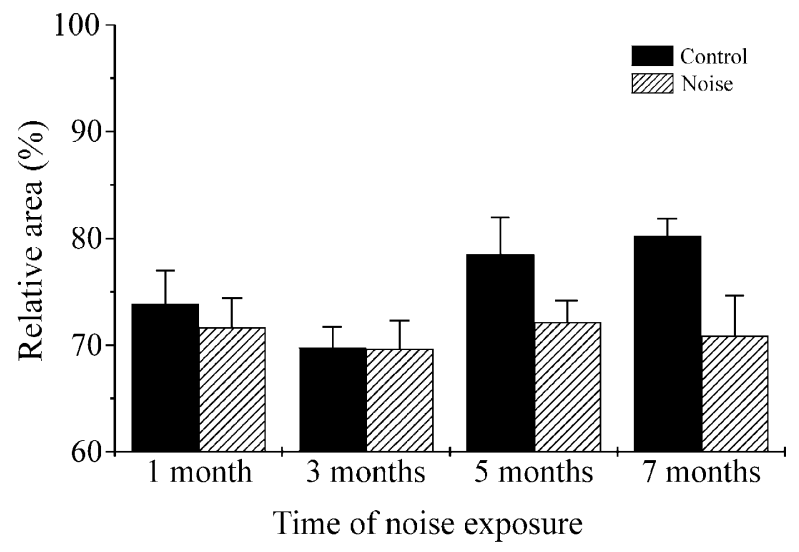

Fig. 5. Relative area occupied by ciliated cells on the bronchial epithelium of Wistar rat after 1, 3, 5, and 7 months of noise exposure and their age-matched controls. Statistical comparison revealed that 5and 7 -month-long exposures to noise caused significant $(P<0.05)$ decrease in the relative area of bronchi occupied by ciliated cells compared with values from age-matched controls. These differences are due to the physiological enhancement in the area occupied on the bronchial lining by ciliated cells in the control rats, as they grow older, a phenomenon that is abrogated in noise-exposed animals.

inhibited this enhancement in the cilia-coated area of bronchi: a 5-month-long exposure to noise caused a statistically significant decrease in the bronchial area covered by ciliated cells, in comparison with similar values from aged-matched control animals. This phenomenon was also observed after 7 months of noise exposure of the animals (Fig. 5). Therefore, it can be concluded that the herein reported differences in bronchial cytology between noise-exposed and control rats is the result of abrogation by noise of the physiological enhancement in relative area of ciliated cells that is observed on bronchial epithelium of young rats as they grow a few months older.

\section{Discussion}

Experimental exposure of Wistar rats to textile noise resulted in statistically significant differences between noise-exposed and control age-matched rats, after 5 and 7 months of treatment of the animals. These quantitative differences are due to the noise-induced arrest in the normal increase in the proportion of ciliated cells that coat the bronchial lining in young adult rats as they grow a few months older. Therefore, it is pertinent to propose that noise exposure interferes with ciliated cell expansion on the bronchial epithelium. This change is of particular importance because ciliated cells are key players in mucociliar clearance of the respiratory tract (Bertrand et al., 2000).

In a previous study it was shown that chronic exposure of experimental animals to the textile noise is able to alter the ciliated/secretory cell ratio on the 
tracheal epithelium (Pereira et al., 1999). In fact, it was observed that excessive noise causes loss of ciliated cells that leads to a compensatory increase in secretory cells in the trachea (Pereira et al., 1999). The herein data taken together with these previous findings suggest that a moderate impairment of the mucociliary apparatus may occur in the respiratory tract in response to chronic exposure to textile noise.

Workers of the textile industry show enhanced prevalence of respiratory disorders that have been interpreted as a consequence of organic dust inhalation (Fishwick et al., 1996; Cloutier and Guernsey, 1998; Simpson et al., 1998; Raza et al., 1999). This may lead to a pneumoconiosis known as byssinosis that has a complex etiology involving other factors in addition to the inhalation of textile fibers (Heederik and Douwes, 1997; Douwes et al., 2003). Among these factors are airborne endotoxins that are known to be present in the working environments of textile industries (Douwes and Heederik, 1997; Douwes et al., 2002).

The current results point to chronic noise as a contributing factor for the respiratory dysfunctions observed in textile workers. In fact, in other environments where noise pollution occurs, some workers will develop airflow limitation and moderate interstitial fibrosis of the lung (Castelo Branco, 1999; Reis Ferreira et al., 1999; Grande et al., 1999). Considering the present experimental data, it is pertinent to consider that chronic exposure of textile workers to severe noise may be one of the environmental factors that may explain their increased susceptibility to respiratory ailments.

\section{Acknowledgments}

The authors are very grateful to Dr. Daniela Silva and Professor Carlos Moreira de Sá(CEMUP/UP) for expert help with SEM. We thank Mr. António Costa e Silva, Mrs. Alexandrina Ribeiro, Dr. Madalena Costa, Mr. Emanuel Monteiro, Mr. Duarte Monteiro, and Mr. JoséAurélio Mexedo for technical assistance, Mr. Humberto Andrade Fonseca and Mr. Hugo Silva Santos for help in setting up the animal room for noise exposure, and Dr. Pinto de Almeida for allowing us the use of the industrial facilities where cotton-mill noise was taped. This work was funded by grants from IDICT and FCT (POCTI/FEDER), Portugal.

\section{References}

Alves Pereira, M., 1999. Noise-induced extra-aural pathology: a review and commentary. Aviat. Space Environ. Med. 70, A7-A21.

Bertrand, B., Collet, S., Eloy, P., Rombaux, P., 2000. Secondary ciliary dyskinesia in upper respiratory tract. Acta Otorhinolaryngol. Belg. 54, 309-316.
Castelo Branco, N.A.A., 1999. The clinical stages of vibroacoustic disease. Aviat. Space Environ. Med. 70, A32-A39.

Castelo Branco, N.A.A., Rodriguez, E., 1999. The vibroacoustic disease - an emerging pathology. Aviat. Space Environ. Med. 70, A1-A6.

Cloutier, M.M., Guernsey, L., 1998. Byssinosis: role of polymer length on the effect of tannin on the airway beta-adrenergic receptor. Lung 176, 393-401.

Douwes, J., Heederik, D., 1997. Epidemiologic investigations of endotoxins. Int. J. Occup. Environ. Health 3, S26-S31.

Douwes, J., Pearce, N., Heederik, D., 2002. Does environmental endotoxin exposure prevent asthma?. Thorax 57, 86-90.

Douwes, J., Thorne, P., Pearce, N., Heederik, D., 2003. Bioaerosol health effects and exposure assessment: progress and prospects. Am. Occup. Hyg. 47, 187-200.

Fishwick, D., Fletcher, A.M., Pickering, C.A., McL, N.R., Faragher, E.B., 1996. Lung function in Lancashire cotton and man made fibre spinning mill operatives. Occup. Environ. Med. 53, 46-50.

Grande, N.R., Águas, A.P., Pereira, A.P., Monteiro, E., Castelo Branco, N.A.A., 1999. Morphological changes in rat lung parenchyma exposed to low frequency noise. Aviat. Space Environ. Med. 70, A70-A77.

Harvey, W.R., 1990. Mixed model least-squares and maximum likelihood computer program. User's Guide for LSMLMW and MIXMDL, PC-2 version, Copyright WR Harvey, pp. 1-91.

Heederik, D., Douwes, J., 1997. Towards an occupational exposure limit for endotoxins. Am. Agric. Environ. Med. 4, 17-19.

Knipschild, P., 1977. Medical effects of aircraft noise: review and literature. Int. Arch. Occup. Environ. Health 41, 201-204.

Knipschild, P., 1978. Aircraft noise and hypertension. Proceedings of the Third International Congress on Noise as a Public Health Problem, Freiburg, pp. 283-287.

Knipschild, P., Meijer, H., Sallé, H., 1981. Aircraft noise and birth weight. Int. Arch. Occup. Environ. Health 48, 131-136.

Melamed, S., Bruhis, S., 1996. The effects of chronic industrial noise exposure on urinary cortisol, fatigue and irritability: a controlled field experiment. J. Occup. Environ. Med. 38, 252-256.

Nicholas, J.S., Lackland, D.T., Dosemeci, M., Mohr Jr., L.C., Dunbar, J.B., Grosche, B., Hoel, D.G., 1998. Mortality among US commercial pilots and navigators. J. Occup. Environ. Med. 40, 980-985.

Oliveira, M.J.R., Pereira, A.P., Castelo Branco, N.A.A., Grande, N.R., Águas, A.P., 2002. In utero and postnatal exposure of Wistar rats to low frequency/high intensity noises depletes the tracheal epithelium of ciliated cells. Lung 179, 225-232.

Parvizpoor, D., 1976. Noise exposure and prevalence of high-body pressure among weavers in Iran. J. Occup. Med. 18, 730-731.

Pereira, A.S., Águas, A.P., Grande, N.R., Mirones, J., Monteiro, E., Castelo Branco, N.A.A., 1999. The effect of chronic exposure to low frequency noise on rat tracheal epithelia. Aviat. Space Environ. Med. 70, A86-A90.

Raza, S.N., Fletcher, A.M., Pickering, C.A., Niven, R.M., Faragher, E.B., 1999. Respiratory symptoms in Lancashire textile weavers. Occup. Environ. Med. 56, 514-519.

Reis Ferreira, J.M., Couto, A.R., Jalles-Tavares, N., Castelo Branco, M.S.N., Castelo Branco, N.A.A., 1999. Airway flow limitation in patients with Vibroacoustic Disease. Aviat. Space Environ. Med. 70, A63-A69.

Simpson, J.C., Niven, R.M., Pickering, C.A., Fletcher, A.M., Oldham, L.A., Francis, H.M., 1998. Prevalence and predictors of work related respiratory symptoms in workers exposed to organic dust. Occup. Environ. Med. 55, 668-672.

Zagalo, C., Grande, N.R., Santos, J.M., Monteiro, E., Brito, J., Águas, A.P., 2001. Tracheal transplantation: cytological changes studied by scanning and transmission electron microscopy in the rabbit. Laryngoscope 111, 657-662. 